\section{Optically reconfigurable planar monopole antenna for cognitive radio application}

\author{
Abdul Ali ${ }^{1}$ (i) | Kagan Topalli ${ }^{2}$ । \\ Mehrab Ramzan ${ }^{3}$ । \\ Muhammad Alibakhshikenari ${ }^{1}$ (i) । \\ Talha Masood Khan ${ }^{4}$ | Ayhan Altintas ${ }^{5,6}$ | \\ Paolo Colantonio 1
}

\author{
${ }^{1}$ Department of Electronics Engineering, University of Rome Tor Vergata, \\ Rome, Italy \\ ${ }^{2}$ TUBITAK Space Technologies Research Institute, Ankara, Turkey \\ ${ }^{3}$ Chair of RF Engineering, Communication Laboratory, TU Dresden, \\ Germany \\ ${ }^{4}$ UNAM-Institute of Materials Science and Nanotechnology, Bilkent \\ University, Ankara, Turkey \\ ${ }^{5}$ Department of Electrical and Electronics Engineering, Bilkent University, \\ Ankara, Turkey \\ ${ }^{6}$ Communication and Spectrum Management Research Center (ISYAM), \\ Bilkent University, Ankara, Turkey \\ Correspondence \\ Abdul Ali, Department of Electronics Engineering, University of Rome Tor \\ Vergata, Rome, 00133, Italy. \\ Email: abdul.ali@uniroma2.it \\ Funding information \\ H2020 ITN CELTA, Grant/Award Number: 675683
}

\begin{abstract}
Frequency reconfigurable antenna is one of the important elements needed for cognitive radio application. Such antenna can be designed using highly resistive (HR) silicon ( $\mathrm{Si}$ ) operating as an optical switch. This letter presents a novel frequency reconfigurable planar monopole antenna suitable for cognitive radio application. The antenna is designed using HR Si working as an optical switch. The main idea behind the design of antenna is the redistribution of surface current on the antenna while changing the state of $\mathrm{Si}$ switches optically from high resistance to low resistance. The antenna is highly compact and uses only two switches for multiband reconfiguration. It is switchable on $1.9 \mathrm{GHz}, 2.75 \mathrm{GHz}, 3.7$
\end{abstract}

$\mathrm{GHz}, 4.1 \mathrm{GHz}, 4.6 \mathrm{GHz}, 4.8 \mathrm{GHz}$, and 7.6 to $11 \mathrm{GHz}$ frequency bands. Simulated and measured results are presented for the antenna. To the best of authors knowledge, this is the first multiband optically reconfigurable planar monopole antenna.

\section{KEYWORDS}

cognitive radio, high-resistive (HR) silicon, low-resistive (LR) silicon, multiband, optical excitation, planar monopole antenna, reconfigurable

\section{1 | INTRODUCTION}

Reconfigurable antennas are type of smart antennas which can change their characteristics dynamically such as frequency, polarization, radiation pattern, and main beam direction. Many single-function antennas working on different frequencies can be replaced by reconfigurable antennas thus reducing size and overall cost. Reconfigurable antennas are highly desirable for cognitive radio application, where they can switch their operating frequency dynamically to make use of any available channel. ${ }^{1,2}$

Reconfigurable antenna in its basic form contains a switch and reconfigurable element. The two parts of the antenna are connected in such a way that the former can change the characteristics (frequency, polarization, or main beam direction) of the antenna dynamically. The antenna works on one particular frequency when the switch is inactive (OFF); however, if the switch is activated $(\mathrm{ON})$, then it works on a different frequency. The design of switch and its location on the antenna is critical as it can affect the performance of the latter. ${ }^{3-20}$ Therefore, it is important to make sure that the switch does not affect the performance of the antenna.

Reconfigurable antennas based on nonoptical and optical switches are reported in References 4-13 and 14-20, respectively. Optical switches are preferred over nonoptical switches in designing reconfigurable antennas. Unlike nonoptical switches, they are fast and do not interfere parasitically with the radiation characteristics of the antenna. ${ }^{14-20}$

Most of the optically reconfigurable antennas reported in literature are tuned in two or three frequency bands. ${ }^{14-20}$ For instance, in References 14,15, the length of the printed dipole is dynamically increased with the help of two silicon (Si) switches to make the antenna frequency and polarization 
agile. The authors in Reference 16 have integrated broadband printed antenna with defected microstrip structure (DMS) band-pass filter to make its frequency reconfigurable without changing the dimensions of the antenna. In Reference 17, Franklin array antenna is made reconfigurable using laser diode. In Reference 18, three Si switches are used to change the effective stub impedance seen by the patch antenna using low-power level from the optical source for frequency tuning. Another frequency agile antenna is reported in Reference 19 that uses high-power laser source. All these optically reconfigurable antennas work maximum in three frequency bands, and some of them require powerful laser source for switching operation.

In this letter, a novel optically frequency reconfigurable planar monopole antenna is presented for cognitive radio application. The antenna design adopts two Si samples each behaving as an optical switch. The characteristics of the $\mathrm{Si}$ samples are reported in Reference 3. Unlike previously reported reconfigurable antennas in literature, the antenna here is compact and switchable on multiband frequencies using only two Si switches. The prototype of the antenna is validated by full-wave EM simulation and measured results. A good agreement is found between full-wave EM simulation and measured results. In future, this letter could help engineers in designing various reconfigurable RF and microwave circuits for various applications.

\section{I DESIGN OF RECONFIGURABLE MONOPOLE ANTENNA}

Reconfigurable antenna is the core element of cognitive radio. Typically, cognitive radio consists of ultra wideband (UWB) antenna and reconfigurable antenna. The UWB antenna senses the channel then depending on its availability the reconfigurable antenna switches its operating frequency according to it. ${ }^{1,2}$

For cognitive radio application, we developed a novel optically frequency reconfigurable monopole antenna using the experimental results of $\mathrm{Si}$ with different charge carrier concentration as reported in Reference 3. The main idea behind the design of antenna is the redistribution of surface current on the antenna while changing the state of $\mathrm{Si}$ switches optically from high resistance to low resistance. Figure 1A illustrates the structure along with necessary geometrical parameters of the reconfigurable monopole antenna. The antenna consists of two regions, feeder line connected to a lower rounded triangle, and an upper rounded triangle. The two triangles are connected via two highly resistive (HR) Si switches (S1 and S2). The first switch (S1) directly connects the two regions from the middle of antenna, whereas the second switch (S2) connects the right side of lower triangle via strip to the top of the upper triangle in such a way to make crown-like shape. The advantage regarding such shape arrangement is the overall small size

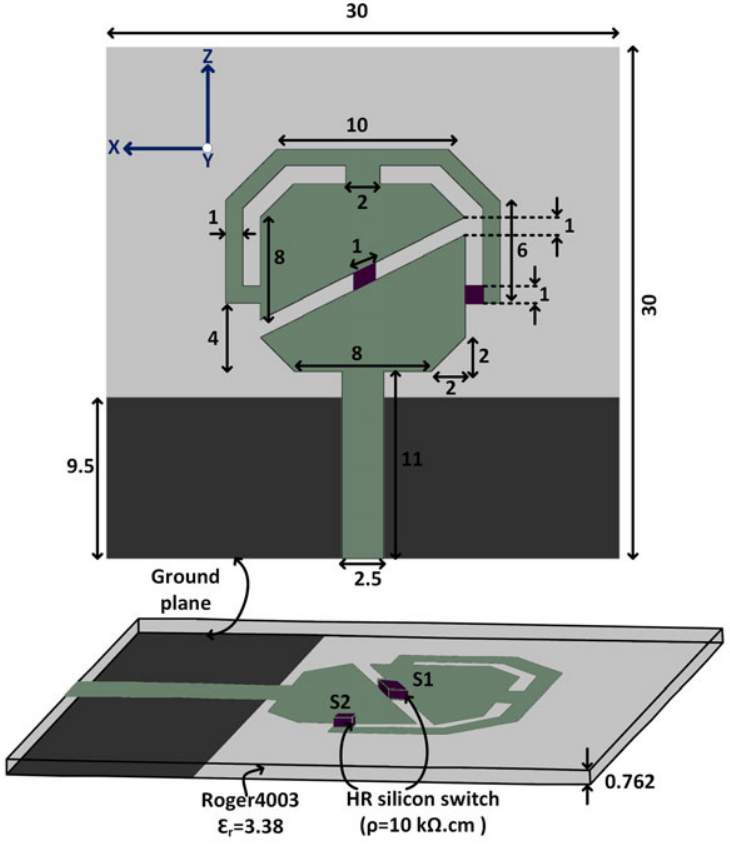

(A)

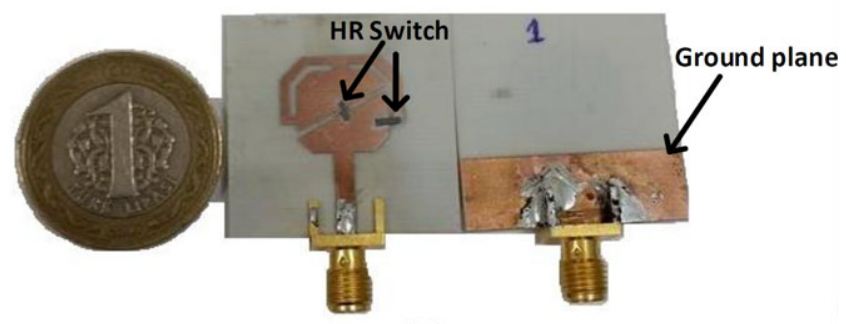

(B)

FIGURE 1 A, Geometry of reconfigurable monopole antenna (all dimensions in $\mathrm{mm}$ ) and $\mathrm{B}$, fabricated prototype [Color figure can be viewed at wileyonlinelibrary.com]

and multiband reconfiguration of the antenna. Reconfigurability is achieved by changing the two switch positions in ON, OFF fashion which causes the surface current to redistribute on the antenna through different paths. Thus, looking from the feed point, the antenna can see different effective lengths. The size and resistivity $(\rho)$ of each HR Si switch are $1 \mathrm{~mm} \times 1 \mathrm{~mm} \times 0.5 \mathrm{~mm}$ and $10 \mathrm{k} \Omega \mathrm{cm}$, respectively. The overall size of the antenna is $30 \mathrm{~mm} \times 30 \mathrm{~mm}$. To simulate the antenna along with switches in CST Microwave Studio ${ }^{\circledR}$, we assumed the ON/OFF resistance of HR Si as characterized in Reference 3. The antenna is fabricated using $0.762 \mathrm{~mm}$ thick RO4003 substrate via rapid PCB prototyping equipment. Figure 1B shows the photograph of the fabricated antenna with the HR Si switches placed on it.

\section{1 | Reflection coefficient of the antenna}

A low-resistive (LR) Si with resistivity, $\rho$, of 1 to $10 \Omega \mathrm{cm}$ can be used to mimic the ON state conductivity of HR Si as discussed in References 3,21. The room temperature conductivity of LR Si is similar to that of HR Si illuminated by laser 
source with power $\geq 50 \mathrm{~mW}$. $^{3,21}$ Therefore, LR Si can be used to measure the return loss of the antenna in ON state of the switches. For reflection coefficient measurement, four antennas are fabricated that covers the four cases of switch positions (S1 \& S2 OFF, S1 ON \& S2 OFF, S1 OFF \& S2 $\mathrm{ON}$, and $\mathrm{S} 1 \mathrm{ON} \& \mathrm{~S} 2 \mathrm{ON}$ ). A combination of LR and HR Si are bonded at the desired location on the fabricated antennas using silver epoxy. These combinations ( $\mathrm{S} 1=\mathrm{HR}, \mathrm{S} 2=\mathrm{HR}$ ), $(\mathrm{S} 1=\mathrm{LR}, \mathrm{S} 2=\mathrm{HR}),(\mathrm{S} 1=\mathrm{HR}, \mathrm{S} 2=\mathrm{LR})$, and $(\mathrm{S} 1=\mathrm{LR}$, $\mathrm{S} 2=\mathrm{LR}$ ) are representing ALL OFF, S1 ON, S2 ON, and ALL ON, respectively.

Figure 2 shows the simulated and measured reflection coefficients of the antenna for different switch positions. Multiband reconfigurability is clearly visible from $S_{11}$ graphs. There is slight shift of $100 \mathrm{MHz}$ in the measurement

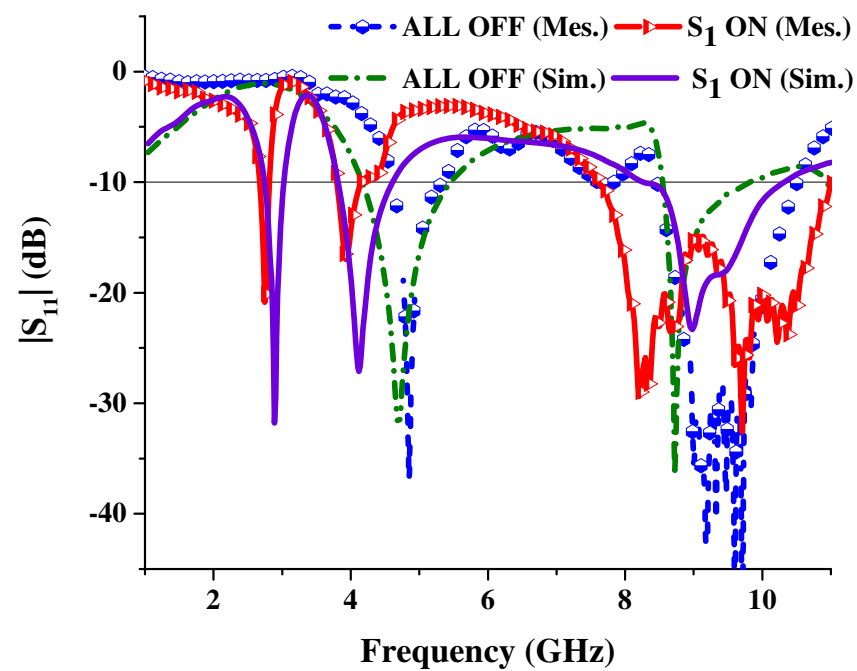

(A)

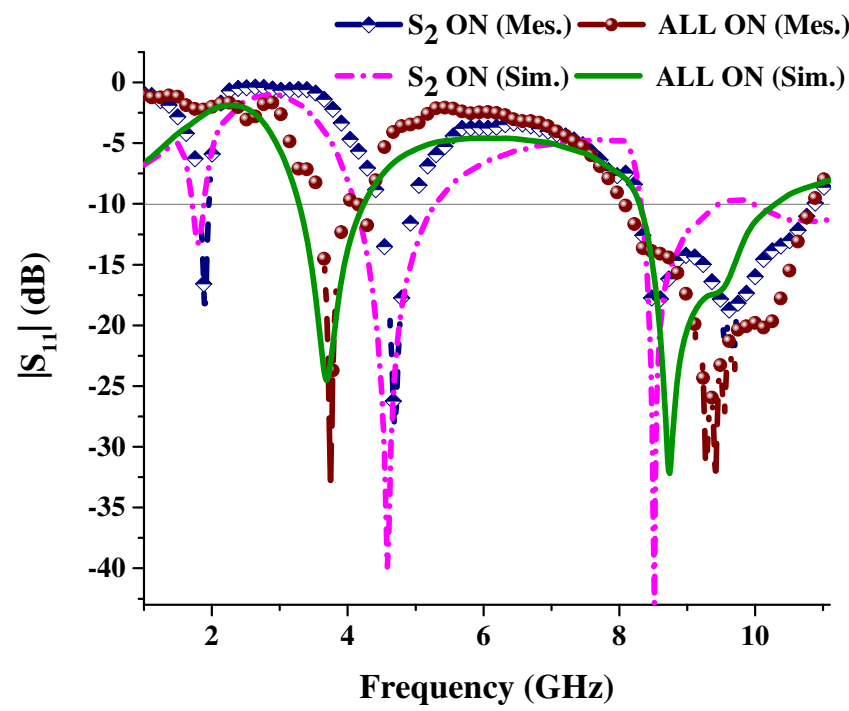

(B)

FIGURE 2 Measurement and simulation results for the reflection coefficient of the antenna for different switch positions [Color figure can be viewed at wileyonlinelibrary.com] results. However, generally, a good agreement is noticed between simulated and measured results.

\subsection{Surface current distribution on the antenna}

The operating frequencies of the antenna can be grasped from the surface current distribution on the antenna.
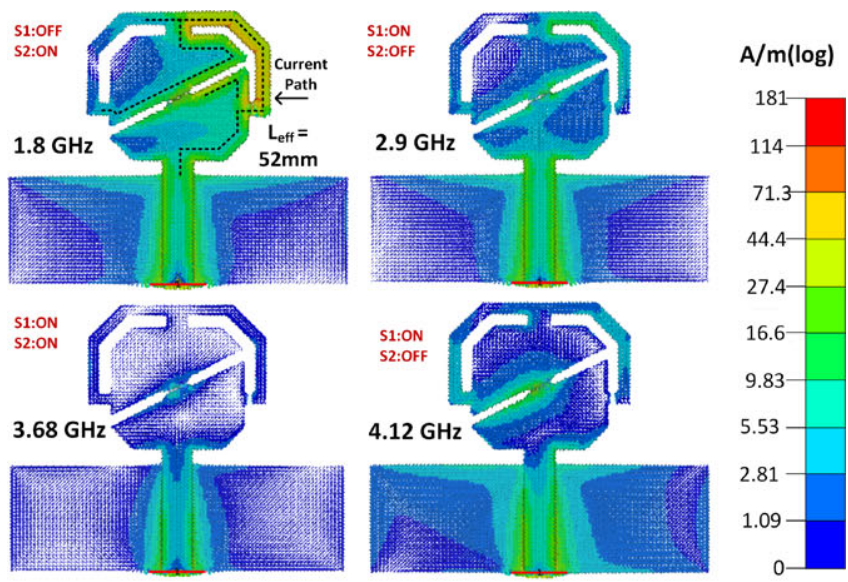

(A)
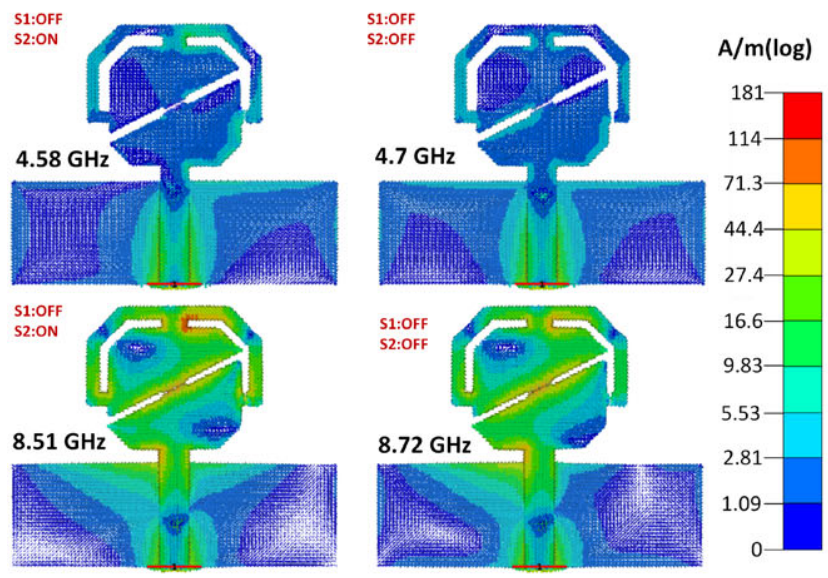

(B)

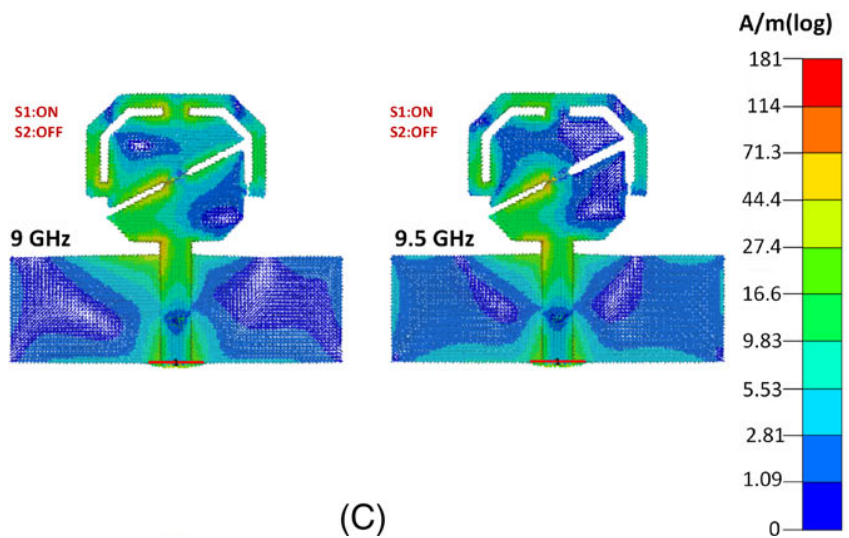

FIGURE 3 Simulated surface current distribution at different resonance frequency [Color figure can be viewed at wileyonlinelibrary.com] 


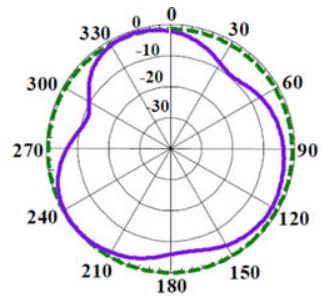

(A)
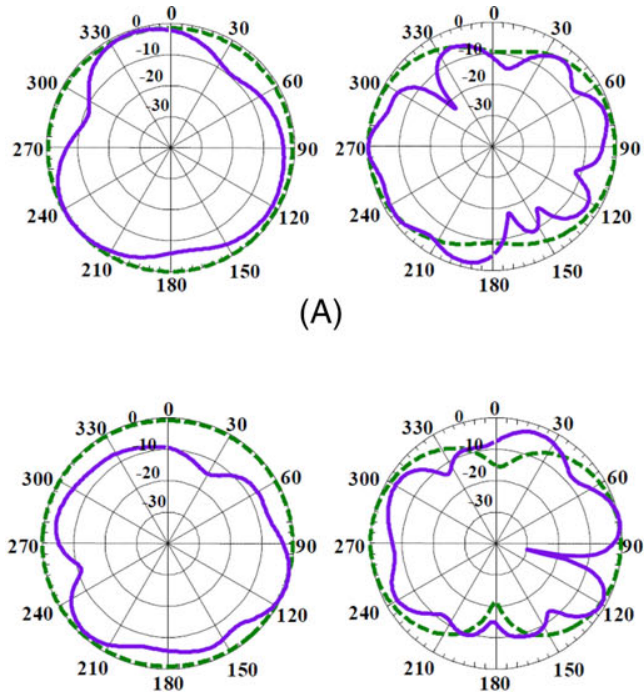

(C)
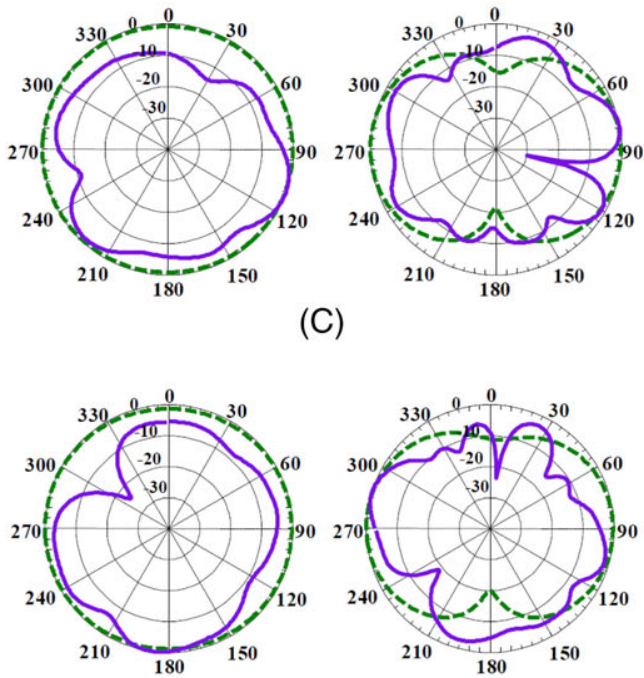

(E)
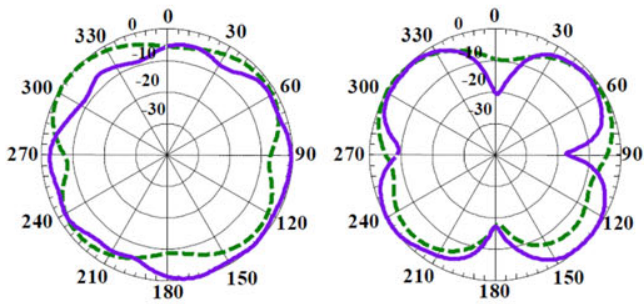

(G)

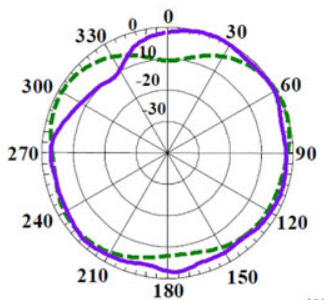

(I)

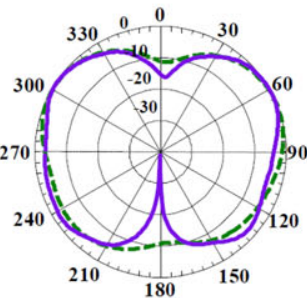

)

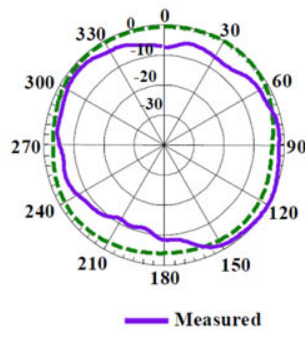

xy-plane
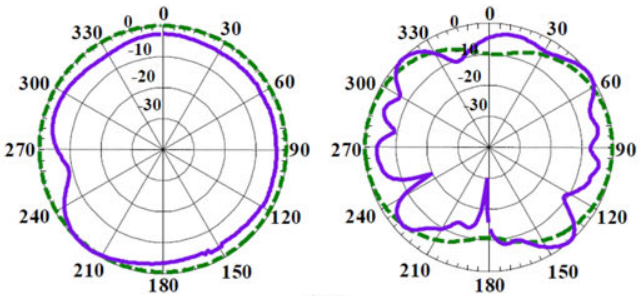

(B)
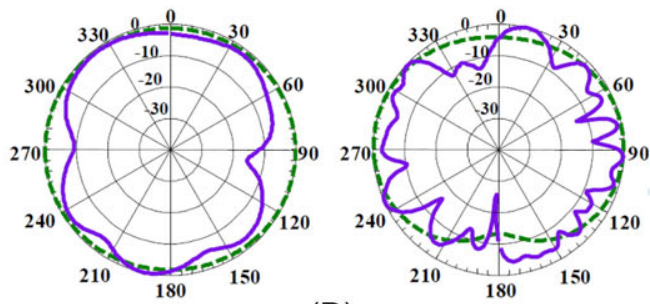

(D)
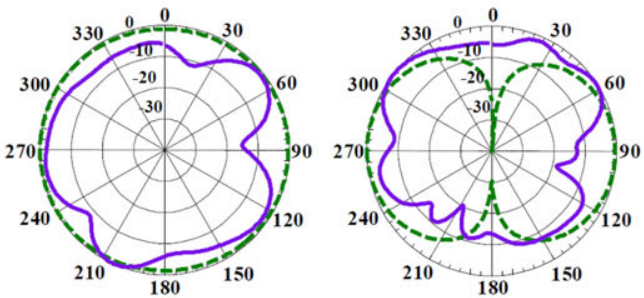

(F)
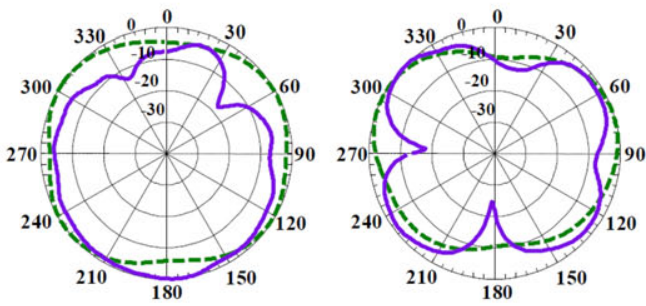

(H)

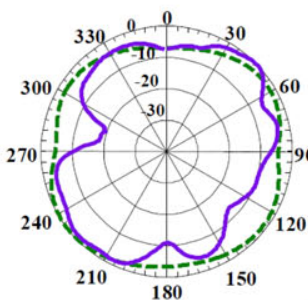

(J)
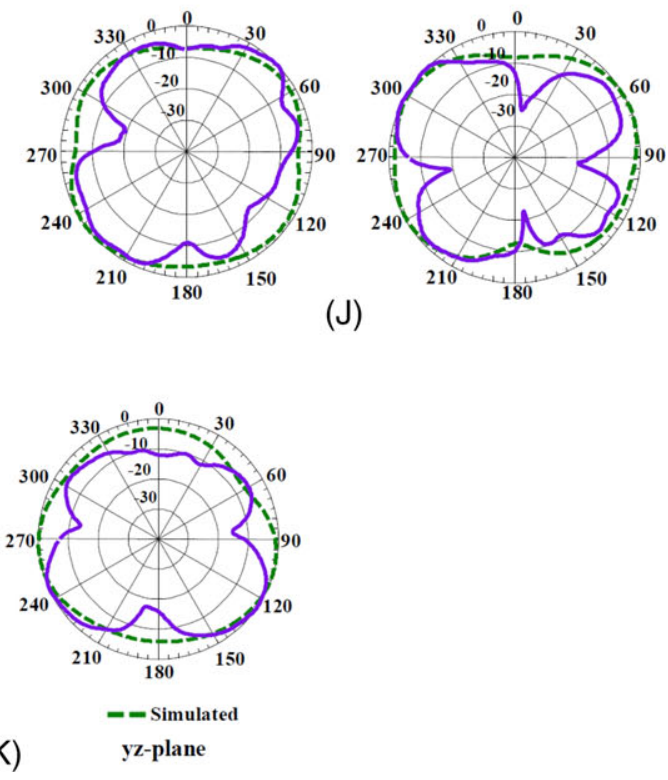

FIGURE 4 Measured (solid line) and simulated (dash line) normalized radiation patterns of the monopole antenna in the $x y$-plane (left side) and yz-plane (right side) at: A, $1.9 \mathrm{GHz} ; \mathrm{B}, 2.75 \mathrm{GHz}$ C, 3.7 GHz; D, $4.1 \mathrm{GHz}$; E, 4.6 GHz; F, 4.8 GHz; G, $8.51 \mathrm{GHz} ; \mathrm{H}, 8.9 \mathrm{GHz} ; \mathrm{I}$, $9 \mathrm{GHz}$; J, $9.7 \mathrm{GHz}$; and $\mathrm{K}, 11 \mathrm{GHz}$ [Color figure can be viewed at wileyonlinelibrary.com] 
TABLE 1 Simulated gain and radiation efficiency of the antenna

\begin{tabular}{lll} 
Frequency $(\mathbf{G H z})$ & Gain $(\mathbf{d B i})$ & Efficiency $(\%)$ \\
\hline 1.9 & 1.2 & 51.42 \\
2.75 & 1.33 & 74.7 \\
3.7 & 1.6 & 87 \\
4.1 & 1.74 & 92 \\
\hline 4.6 & 1.94 & 91 \\
4.8 & 2 & 91.7 \\
8.51 & 4.13 & 94 \\
8.9 & 4.62 & 93 \\
9 & 4.81 & 93 \\
9.7 & 4.05 & 86.8 \\
11 & 5.3 & 85 \\
\hline
\end{tabular}

Therefore, in this section, we provided some examples of current distribution and related resonances. Figure 3 shows simulated surface current distribution at various resonance frequencies.

In ALL OFF case, the antenna resonates at two frequencies $(4.7 \mathrm{GHz}$ and $8.72 \mathrm{GHz})$. Although the two switches are OFF, still, there is strong surface current at $8.72 \mathrm{GHz}$ at the upper region of the antenna containing the crown-like shape (see Figure 3). The size of this region is comparable to the wavelength at these two frequencies causing strong induced current. However, at $4.7 \mathrm{GHz}$, the surface current is mainly concentrated at the feed line and the ground plane near it. In addition, there is some current at the outer boundary of the antenna.

When $\mathrm{S} 1$ is $\mathrm{ON}$ and $\mathrm{S} 2$ is OFF, the surface current redistributes from lower region to upper region via $\mathrm{S} 1$ which causes four resonances $(2.9 \mathrm{GHz}, 4.12 \mathrm{GHz}, 9 \mathrm{GHz}$, and 9.5 GHz). The surface current at $2.9 \mathrm{GHz}$ and $4.12 \mathrm{GHz}$ is mainly concentrated in regions near switch $\mathrm{S} 1$, feed line, and ground plane near the feed line. However, the current in the lower region of the antenna is stronger at $2.9 \mathrm{GHz}$ than 4.12 GHz. Moreover, the surface current is stronger at the right side of the antenna at $9 \mathrm{GHz}$ and $9.5 \mathrm{GHz}$. The electrical size of the antenna at these two frequencies is almost half of a wavelength, if we look at region where current is stronger. The OFF state of S2 is causing weak current at the left side of the antenna. As a matter of fact, because the current distribution at $9 \mathrm{GHz}$ is covering almost half a wavelength on the antenna, as a consequence, we expect a dipole-like radiation pattern from the antenna at this frequency. It will be demonstrated in the following section where radiation patterns of the antenna are discussed that at this frequency, the antenna provides donut-like radiation pattern.

When S2 is ON and S1 is OFF, the surface current redistributes from lower region to upper region via $\mathrm{S} 2$ which causes three resonances $(1.8 \mathrm{GHz}, 4.58 \mathrm{GHz}$, and $8.51 \mathrm{GHz})$. At these frequencies, the current is mainly concentrated at the left side of the antenna except at $8.51 \mathrm{GHz}$, which also has strong current at right side of the antenna. Furthermore, the lowest resonance frequency can be estimated from the longest effective surface current path $\left(L_{\text {eff }}=\lambda_{\text {eff }} / 2\right){ }^{22}$ Of note, $1.8 \mathrm{GHz}$ is the lowest frequency of the antenna in simulation, and the $L_{\text {eff }}$ is approximated using the method described in Reference 22. Figure 3 shows the current path for $L_{\text {eff }}=52 \mathrm{~mm}$. The lowest frequency $\left(f=c / \lambda_{\text {eff }}, \lambda_{\text {eff }}=2\right.$ $L_{\text {eff }} \sqrt{\left(\varepsilon_{\mathrm{r}}+1\right) / 2}$ is $1.94 \mathrm{GHz} .^{22}$ The measured results show that the lowest resonant frequency is $1.9 \mathrm{GHz}$ which is quite close to the calculated value. The reason for small difference in measurement and simulated lowest frequency can be due to simulation inaccuracy.

Finally, when both switches are in the ON state, a new resonance appears at $3.68 \mathrm{GHz}$. The surface current is mainly concentrated on the feed line and ground near it.

\section{3 | Radiation patterns on the antenna}

To determine the radiation characteristic of the antenna, we measured the radiation patterns of the antenna in anechoic chamber in $x y$ and $y z$ plane. Figure 4 shows the simulated and measured normalized radiation patterns of the antenna at different resonance frequencies in $x y$ and $y z$ plane. There is a good agreement between simulated and measured patterns of the antenna. The experimental results are proof of an omnidirectional behavior from monopole antenna except at certain frequencies where this behavior is slightly distorted. The reason for that is the marginal distribution of the surface current on the antenna. Although the antenna has asymmetric geometry, the radiation patterns are almost symmetric. The omni-directional behavior of the antenna shows that it could be an ideal candidate for various wireless applications.

The simulated gain and total radiation efficiency of the antenna are tabulated in Table 1 at several resonance frequencies. The antenna gain is varying from 1.2 to $5.3 \mathrm{dBi}$. However, the radiation efficiency is varying from $70 \%$ to $94 \%$ except at $1.9 \mathrm{GHz}$ where efficiency drops to $51.42 \%$. The small efficiency at $1.9 \mathrm{GHz}$ is due to the small electrical size of the antenna at this frequency. At high frequency, the electrical size of the antenna is large enough to give high gain and efficiency. These crucial results together with the frequency reconfigurability of the compact monopole antenna allow it to be used for cognitive radio and handheld portable devices.

\section{3 | CONCLUSIONS}

This letter presents a novel design of optically reconfigurable antenna for cognitive radio application. The multiband reconfigurable antenna is designed by using $\mathrm{HR} \mathrm{Si}$ pieces acting as optically tunable resistors. This concept is demonstrated in terms of experimental reflection coefficient and radiation patterns of the antenna. The frequency reconfigurability of the antenna is visible from the return loss plots. The omni-directional radiation behavior of the antenna shows that the antenna is suited for various wireless applications. 
In future, various optically reconfigurable antennas can be designed for $5 \mathrm{G}$ or next generation wireless networks. This method can be applied to design multiband polarization and pattern agile antennas.

\section{ACKNOWLEDGMENT}

The authors thank the H2020 ITN CELTA under grant number 675683 of Call: H2020-MSCA-ITN-2015.

\section{ORCID}

Abdul Ali $\mathbb{D}$ https://orcid.org/0000-0002-0095-6702

Muhammad Alibakhshikenari (D) https://orcid.org/0000-0001-6074-8019

\section{REFERENCES}

[1] Tawk Y, Costantine J, Christodoulou CG. Cognitive-radio and antenna functionalities: a tutorial [wireless corner]. IEEE Antennas Propag Mag. 2014;56(1):231-243.

[2] Aboufoul T, Alomainy A, Parini C. Reconfiguring uwb monopole antenna for cognitive radio applications using GaAs fet switches. IEEE Antennas Wirel Propag Lett. 2012;11:392-394.

[3] Ali A, Topalli K, Ramzan M, Khan TM, Altintas A, Colantonio P. Optical characterization of high and low resistive silicon samples suitable for reconfigurable antenna design. Microw Opt Technol Lett. 2019;61:107-110. https://doi.org/10.1002/mop.31506.

[4] Majid HA, Kamal M, Rahim A, et al. Reconfigurable notched wideband antenna using ebg structure. Microw Opt Technol Lett. 2014;57(2):497-501. [Online]. Available: https://onlinelibrary. wiley.com/doi/abs/10.1002/mop.28882.

[5] Nikolaou S, Bairavasubramanian R, Lugo C, et al. Pattern and frequency reconfigurable annular slot antenna using pin diodes. IEEE Trans Antennas Propag. 2006;54(2):439-448.

[6] Lai MI, Wu TY, Hsieh JC, Wang CH, Jeng SK. Design of reconfigurable antennas based on an 1-shaped slot and pin diodes for compact wireless devices. IET Microw Antenna Propag. 2009;3(1):47-54.

[7] Goncalves R, Pinho P, Carvalho NB. Compact, frequency reconfigurable, printed monopole antenna. Int J Antennas Propag. 2012; 2012:1-6.

[8] Pringle LN, Harms PH, Blalock SP, et al. A reconfigurable aperture antenna based on switched links between electrically small metallic patches. IEEE Trans Antennas Propag. 2004;52(6):1434-1445.

[9] Tawk Y, Costantine J, Christodoulou CG. A varactor-based reconfigurable filtenna. IEEE Antennas Wirel Propag Lett. 2012;11:716-719.

[10] Tariq A, Ghafouri-Shiraz H. Frequency-reconfigurable monopole antennas. IEEE Trans Antennas Propag. 2012;60(1):44-50.
[11] Zohur A, Mopidevi H, Rodrigo D, Unlu M, Jofre L, Cetiner BA. Rf mems reconfigurable two-band antenna. IEEE Antennas Wirel Propag Lett. 2013;12:72-75.

[12] Chiu CY, Li J, Song S, Murch RD. Frequency-reconfigurable pixel slot antenna. IEEE Trans Antennas Propag. 2012;60(10): 4921-4924.

[13] Erdil E, Topalli K, Unlu M, Civi OA, Akin T. Frequency tunable microstrip patch antenna using rf mems technology. IEEE Trans Antennas Propag. 2007;55(4):1193-1196.

[14] Panagamuwa CJ, Chauraya A, Vardaxoglou JC. Frequency and beam reconfigurable antenna using photoconducting switches. IEEE Trans Antennas Propag. 2006;54(2):449-454.

[15] Panagamuwa CJ, Vardaxoglou JC. Optically reconfigurable balanced dipole antenna. Paper presented at: Twelfth International Conference on Antennas and Propagation, 2003 (ICAP 2003). (Conf. Publ. No. 491); vol. 1; March 2003; pp. 237-240.

[16] Silva LG, Alves AAC, Sodr AC. Optically controlled reconfigurable filtenna. Int J Antennas Propag. 2016;2016:1-9.

[17] Collett MA, Gamlath CD, Cryan MJ. Optically induced conductivity in silicon: an active control technique for antennas. Microw Opt Technol Lett. 2016;58(4):994-998. [Online]. Available: https://onlinelibrary.wiley.com/doi/abs/10.1002/mop.29713.

[18] Pendharker S, Shevgaonkar RK, Chandorkar AN. Optically controlled frequency-reconfigurable microstrip antenna with low photoconductivity. IEEE Antennas Wirel Propag Lett. 2014;13:99-102.

[19] Tawk Y, Albrecht AR, Hemmady S, Balakrishnan G, Christodoulou CG. Optically pumped frequency reconfigurable antenna design. IEEE Antennas Wirel Propag Lett. 2010;9:280-283.

[20] Tawk Y, Costantine J, Hemmady S, Balakrishnan G, Avery K, Christodoulou CG. Demonstration of a cognitive radio front end using an optically pumped reconfigurable antenna system (opras). IEEE Trans Antennas Propag. 2012;60(2):10751083.

[21] Callister WD, Rethwisch DG. Materials Science and Engineering: An Introduction. 9th ed. Wiley: New York; 2013.

[22] Chen ZN, See TSP, Qing X. Small printed ultrawideband antenna with reduced ground plane effect. IEEE Trans Antennas Propag. 2007;55(2):383-388.

How to cite this article: Ali A, Topalli K, Ramzan $\mathrm{M}$, et al. Optically reconfigurable planar monopole antenna for cognitive radio application. Microw Opt Technol Lett. 2019;61:1110-1115. https://doi.org/10.1002/mop.31678 